\title{
MAPEAMENTO DOS ESPAÇOS PÚBLICOS DE LAZER DO MUNICÍPIO DE DIVINÓPOLIS - MG
}

Recebido em: $31 / 12 / 2020$

Aprovado em: 17/05/2021 Licença:@) @ @

\author{
Isabella Carolina Silva Pereira ${ }^{1}$ \\ Cacilda Mendes dos Santos Amaral ${ }^{2}$ \\ Universidade do Estado de Minas Gerais (UEMG) - Unidade Divinópolis \\ Divinópolis - MG - Brasil
}

RESUMO: O estudo teve como objetivo mapear os espaços públicos de lazer do município de Divinópolis (MG), observando as distribuições territoriais e os conteúdos de lazer. Trata-se de uma pesquisa descritiva e qualitativa, através de pesquisa documental. Foram analisadas 109 Leis, 7 Decretos e 1 Indicação municipais para identificar espaços públicos de lazer. Foi realizada a classificação dos conteúdos de lazer e a identificação dos espaços e equipamentos de acordo com as distribuições territoriais. Foi possível verificar a predominância dos conteúdos sociais e físicoesportivos, e maior evidência de espaços públicos de lazer na região central e sudeste da cidade, evidenciando que a distribuição não é igualitária entre as regiões, sendo as periféricas menor assistidas. Para pesquisas futuras indicamos a investigação da conservação dos espaços, e análise dos programas de lazer desenvolvidos pelo poder público.

PALAVRAS-CHAVE: Mapeamento geográfico. Atividades de lazer. Política pública.

\section{MAPPING THE PUBLIC SPACES OF LEISURE IN THE MUNICIPALITY OF DIVINÓPOLIS - MG}

ABSTRACT: The study aimed map public leisure spaces in the municipality of Divinópolis (MG), observing territorial distributions and leisure content. It is a descriptive and qualitative approach, through documentary research. 109 laws, 7 decrees and 1 municipal indication were analyzed to identify public leisure spaces. The classification of leisure content and the spaces and equipment identification were carried out according to territorial distributions. It was possible to verify the

\footnotetext{
${ }^{1}$ Discente do curso de Educação Física Bacharelado na Universidade do Estado de Minas Gerais Unidade Divinópolis. Possui graduação em Educação Física Licenciatura na Universidade Federal de Viçosa - Campus Florestal. Possui Pós-Graduação em Esportes e Atividade Física para Pessoas com Deficiência pela Universidade Federal de Juiz de Fora. Participante do Grupo de Estudos e Pesquisas Socioculturais em Educação Física e Esporte (GEPESEFE).

${ }^{2}$ Docente no curso de Educação Física na Universidade do Estado de Minas Gerais (UEMG) - Unidade Divinópolis. Doutora e Mestre em Ciências pela Escola de Educação Física e Esporte da Universidade de São Paulo (EEFE - USP), Bacharel em Esporte pela Escola de Educação Física e Esporte da Universidade de São Paulo (EEFE-USP). Pesquisadora líder do Grupo de Estudos e Pesquisas Socioculturais em Educação Física e Esporte (GEPESEFE).
} 
predominance of social and physical-sports content, and greater evidence of public leisure spaces in the central and southeastern city regions, showing that the distribution is not equal among the regions, with the peripheries being the least attended. For future research, we recommend an investigation of the spaces conservation, and analysis of leisure programs developed by government.

KEYWORDS: Geographic mapping. Leisure activities. Public policy.

\section{Introdução}

O lazer apresenta diversas possibilidades no âmbito social, sendo um fator de acesso a direitos sociais de diferentes ordens. Com isso, a habitação, saneamento básico, planejamento urbano, transporte público, meio ambiente, esporte e artes compreende-se nestes campos pelo qual ocorre a atuação estatal de forma direta na vivência do direito social ao lazer (CAMARGO et al., 2019).

Rodrigues e Bramante (2003) relatam que o lazer acontece por uma vontade interna do indivíduo e o tempo disponível que é vivenciado em algum lugar. Este espaço é primeiramente visto como um aspecto de pouca relevância dentro da temática do lazer. Entretanto, o ambiente físico influencia muito além de sua materialidade.

À vista disso, Marcellino (2006) corrobora dizendo que o lazer contribui de forma prazerosa no processo de valorização do patrimônio, com importante papel na revitalização dos espaços e equipamentos. Desta forma, conservando também a memória das cidades, como patrimônios artísticos, arquitetônicos e urbanísticos.

Entretanto, o espaço público vem perdendo seu uso multifuncional, deixando de ser local de convívio e práticas dos contextos de lazer. Neste contexto, a implementação de políticas públicas juntamente com as áreas socioculturais possui importante papel para permitir a ressignificação do espaço urbano, como a manutenção e animação de equipamentos de lazer e esportes (MARCELLINO et al., 2007). 
Levando em consideração que diante a Constituição de 1988 o lazer foi e é considerado um direito social de todos os brasileiros (BRASIL, 1988), sendo assegurado também pelas leis estaduais orgânicas municipais de diversas cidades do país (TEIXEIRA, 2018), as políticas públicas acabam por exercer papel determinante no acesso à locais de prática de esporte, cultura e lazer como um todo para a população.

Mediante o exposto, Santos; Barbosa e Muniz (2018) comentam que deve haver uma mudança no senso críticos de políticas públicas direcionadas a temática do lazer como proposta intervencionista. Uma vez que, deve-se verificar como essas políticas vem sendo elaboradas e aplicadas nas localidades contempladas. Assim, as diversas formas de utilização de espaços públicos relacionados ao esporte e lazer, provem de uma dimensão qualitativa, na iminência de que estes são fenômenos culturais, que possuem importância significativa no contexto de uma cidade (MARANHO et a.l, 2019).

A Lei Orgânica do município de Divinópolis de 1998 sanciona em seus Capítulos VII e IX do Título referente à "Ordem Social” que o poder público garantirá, em parceria com a sociedade civil, outros órgãos governamentais e as empresas, a promoção, o estímulo, a orientação, o apoio, a prática e a difusão da cultura, do esporte, do lazer e do turismo, tendo em vista à autonomia das entidades e associações desportivas quanto a sua organização e funcionamento, à obrigatoriedade de reserva de áreas destinadas a praças e à prática do esporte e do lazer nos projetos de urbanização e de unidades escolares e a recuperação de espaços públicos descaracterizados (CÂMARA MUNICIPAL DE DIVINÓPOLIS, 1998).

A realização do estudo no município de Divinópolis é fundamental dado que não há conhecimento estruturado de sua totalidade de espaços e equipamentos públicos de lazer na cidade. A partir deste conhecimento será possível promover maior utilização 
destes locais para o convívio social e contribuir na elaboração de políticas públicas de acesso ao lazer no município. A partir dos dados coletados pretende-se discutir sobre as ações pertinentes acerca das políticas públicas de esporte e lazer do município, compreender sua distribuição no território, analisar as demandas e deficiências, e contribuir no desenvolvimento do lazer no município.

Lima (2006) ressalta que a investigação da disponibilidade de espaços públicos de lazer nos bairros e a identificação destes nos diferentes aspectos que afetam a utilização da população contribuem para o entendimento do contexto de lazer urbano, bem como para o aprofundamento dessa concepção para discussões posteriores de fins sociais, que proporcionam a elaboração de estratégias para a utilização de forma democrática nas cidades.

Tendo este panorama em vista, o objetivo desse estudo é a realização do mapeamento de espaços públicos de lazer municipais, observando a distribuição territorial das regiões e os diferentes conteúdos de lazer município de Divinópolis (MG).

\section{Materiais e Métodos}

\section{Tipo de Pesquisa}

Trata-se de uma pesquisa descritiva e qualitativa, que se caracteriza quanto aos fins como uma pesquisa documental, que se refere a estudos relacionados a documentos variados que não foram tratados de forma científica ou analítica. Nesta categoria estão os documentos conservados em arquivos de órgãos públicos e instituições privadas, tais como associações científicas, igrejas, sindicatos, partidos políticos, dentre outros (GIL, 2002).

licere, Belo Horizonte, v.24, n.4, dez/2021. 


\section{Local do Estudo}

O local do estudo foi o município de Divinópolis, região Centro-Oeste de Minas Gerais. A povoação deste originou-se historicamente acerca de 200 anos. Divinópolis foi fundada em 13 de janeiro de 1767 por João Pimenta Ferreira, representante de cinquenta famílias que moravam próximo aos Rios Itapecerica e Pará. Em 24 de março de 1770 foi denominada como Arraial do Espírito Santo da Itapecerica, quando o sertanista Manoel Fernandes Teixeira realizou uma doação de terras à igreja, destinadas a povoação da cidade (CAMARA MUNICIPAL DE DIVINÓPOLIS, 2018).

Em 30 de abril de 1890 houve a inauguração da Estação de Henrique Galvão (Estrada de Ferro Oeste de Minas/ EFOM), que proporcionou um impulso civilizatório, criando condições para a emancipação (PREFEITURA DE MUNICIPAL DE DIVINÓPOLIS). Batista (2002) ressalta que este foi um acontecimento que gerou transformações econômicas, sociais e político-culturais importantes para o delineamento da cidade. Em $1^{\circ}$ de junho de 1912 foi instalado oficialmente o município de Divinópolis.

Este município apresenta atualmente área territorial de $708,115 \mathrm{~km}^{2}$, com densidade demográfica de 300,82 habitantes por quilometro quadrado e população estimada de 238,230 mil habitantes (IBGE, 2010). Dados do IBGE (2017), também relatam que Produto Interno Bruto (PIB) per capita da cidade é no valor de $\mathrm{R} \$ 25.695,97$ e o salário médio mensal dos trabalhadores formais é estimado por 2,1 salários mínimos.

A localização do município de Divinópolis é dividida por regiões, sendo estas caracterizadas como principais, distantes e rurais. As principais são constituídas pela região sudeste contendo aproximadamente 36 bairros, sudoeste com 19 bairros, nordeste com 19 bairros, central com 14 bairros, oeste com 14 bairros e noroeste com 22 bairros. 
As regiões distantes são formadas por sudoeste distante com 26 bairros, nordeste distante com 16 bairros e noroeste distante com 8 bairros. E por fim, as regiões rurais são compostas por sudoeste rural com 13 bairros e noroeste rural com 29 bairros. (Figura 1).

Figura 1: Mapa de localização por regiões do município de Divinópolis - MG

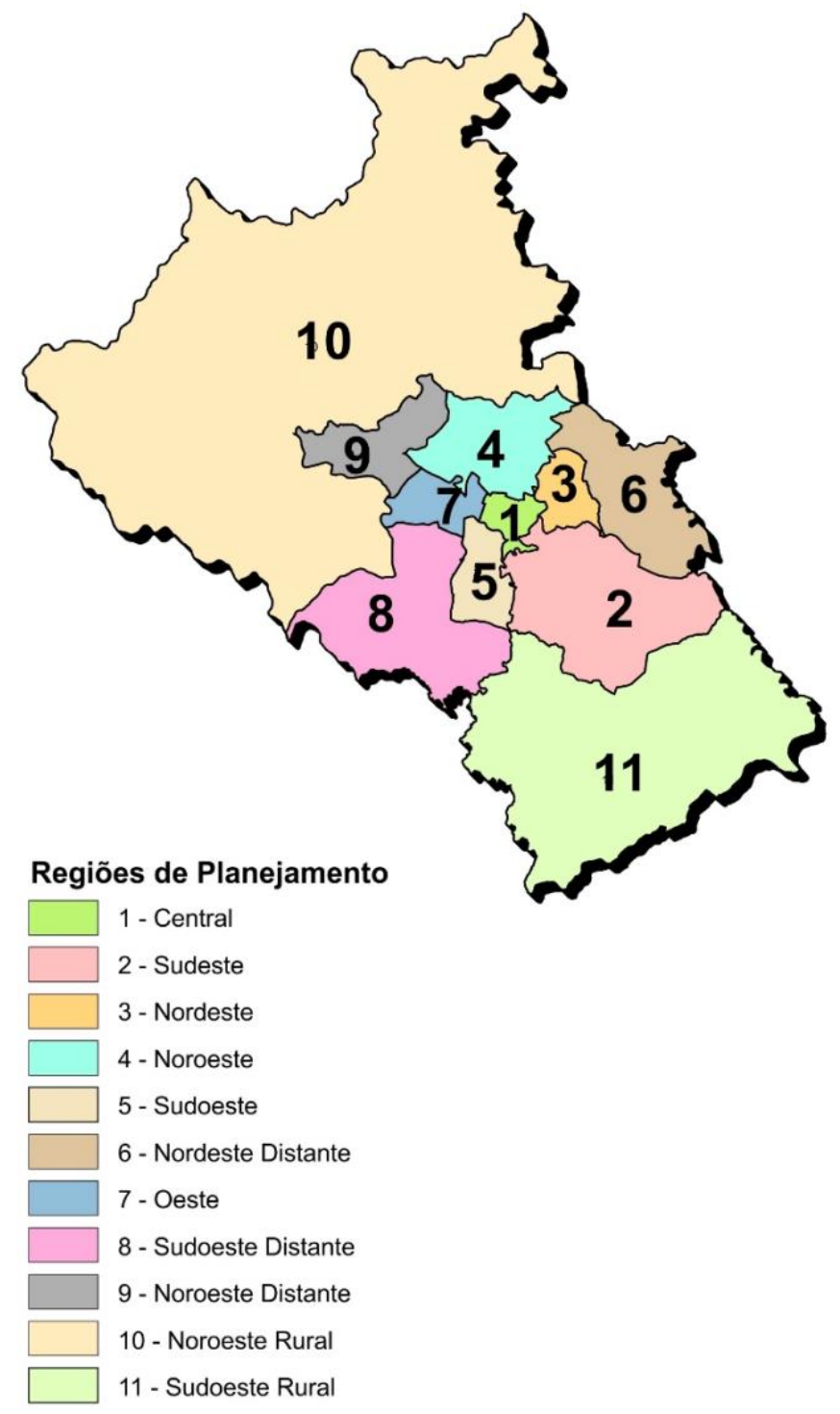

Fonte: Adaptado de Plano Diretor de Divinópolis (2013).

\section{Amostra e Procedimentos de Coleta de Dados}

O estudo teve início a partir da pesquisa documental com a investigação de documentos da Prefeitura de Divinópolis, seguindo um processo de duas etapas:

licere, Belo Horizonte, v.24, n.4, dez/2021. 
- Primeira etapa: Documentos oficiais, como a Lei Orgânica, Plano Diretor e outras leis do próprio município;

- Segunda etapa: Sites, redes sociais, e outros meios online de divulgação oficiais do município.

Para a busca no site da Câmara Municipal de Divinópolis e no site da Prefeitura, foram utilizadas as palavras-chaves: Poliesportivo, Ginásio, Quadra esportiva, Complexo esportivo, Estádio, Campo de Futebol, Praças, Praça, Pista, Ciclovia, Pista de cooper, Lazer, Biblioteca e Tombamento. Abaixo apresentamos o fluxograma demonstrando as legislações obtidas nas buscas e processo de escolha para inclusão na pesquisa.

Figura 2 - Organograma do processo de inclusão e exclusão das legislações no estudo

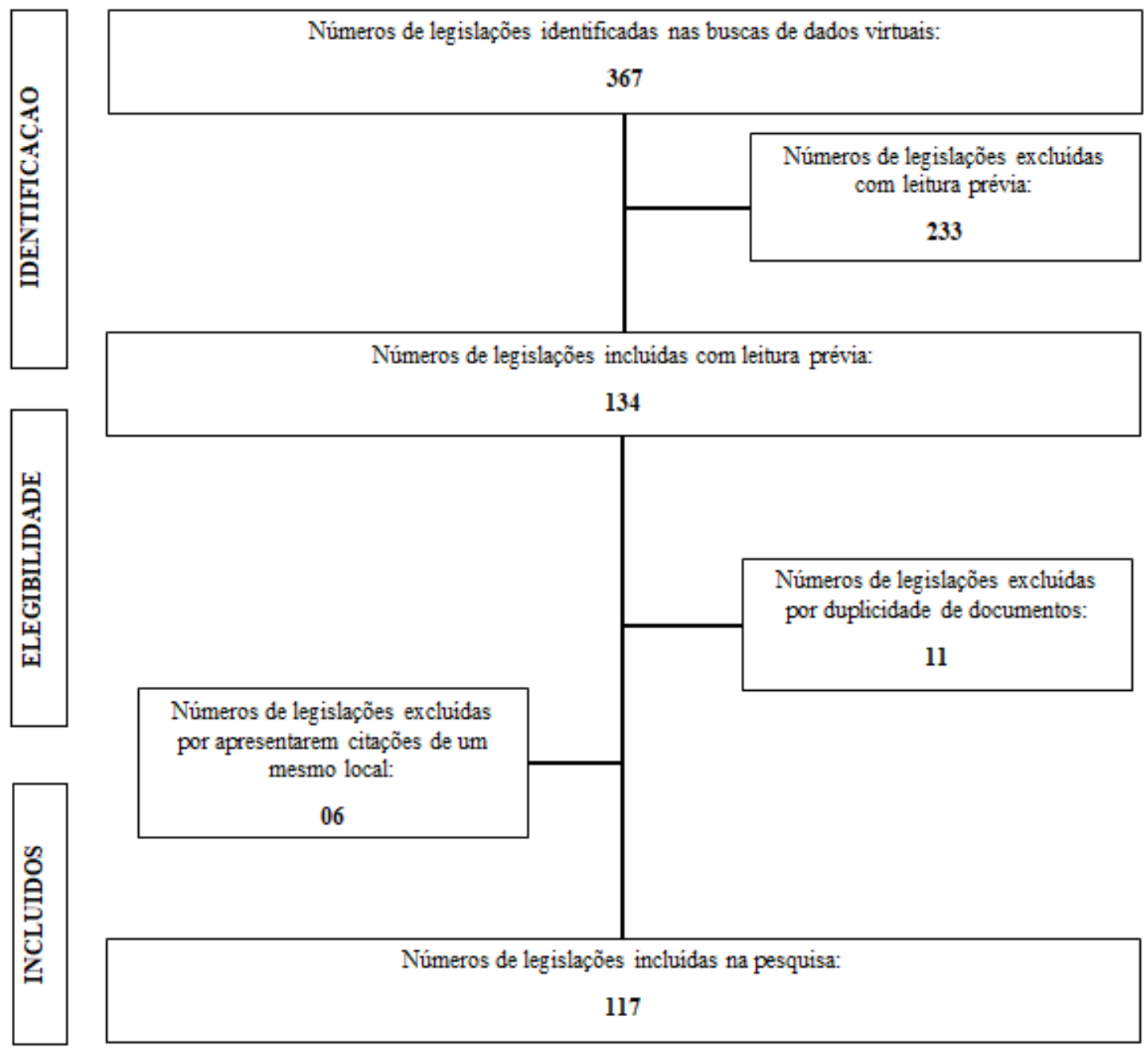

Fonte: Dados da pesquisa

licere, Belo Horizonte, v.24, n.4, dez/2021. 
Como critério de inclusão do estudo, foi determinado que o documento deveria ter acesso público e o corpo do texto deveria conter informações sobre as áreas de lazer. Já como critério de exclusão, aqueles documentos que apresentavam duplicidade e aqueles que citavam a mesma área de lazer que outra legislação, sendo escolhida apenas aquela mais recente que tratasse do mesmo espaço/área.

Desta forma, o Quadro 1 apresenta os documentos detalhados que foram incluídos nesta pesquisa, num total de 109 Leis, 7 Decretos e 1 Indicação.

\section{Quadro 1: Documentos Incluídos no Estudo}

\begin{tabular}{|c|c|}
\hline Tipo do Documento & Detalhamento \\
\hline LEIS & 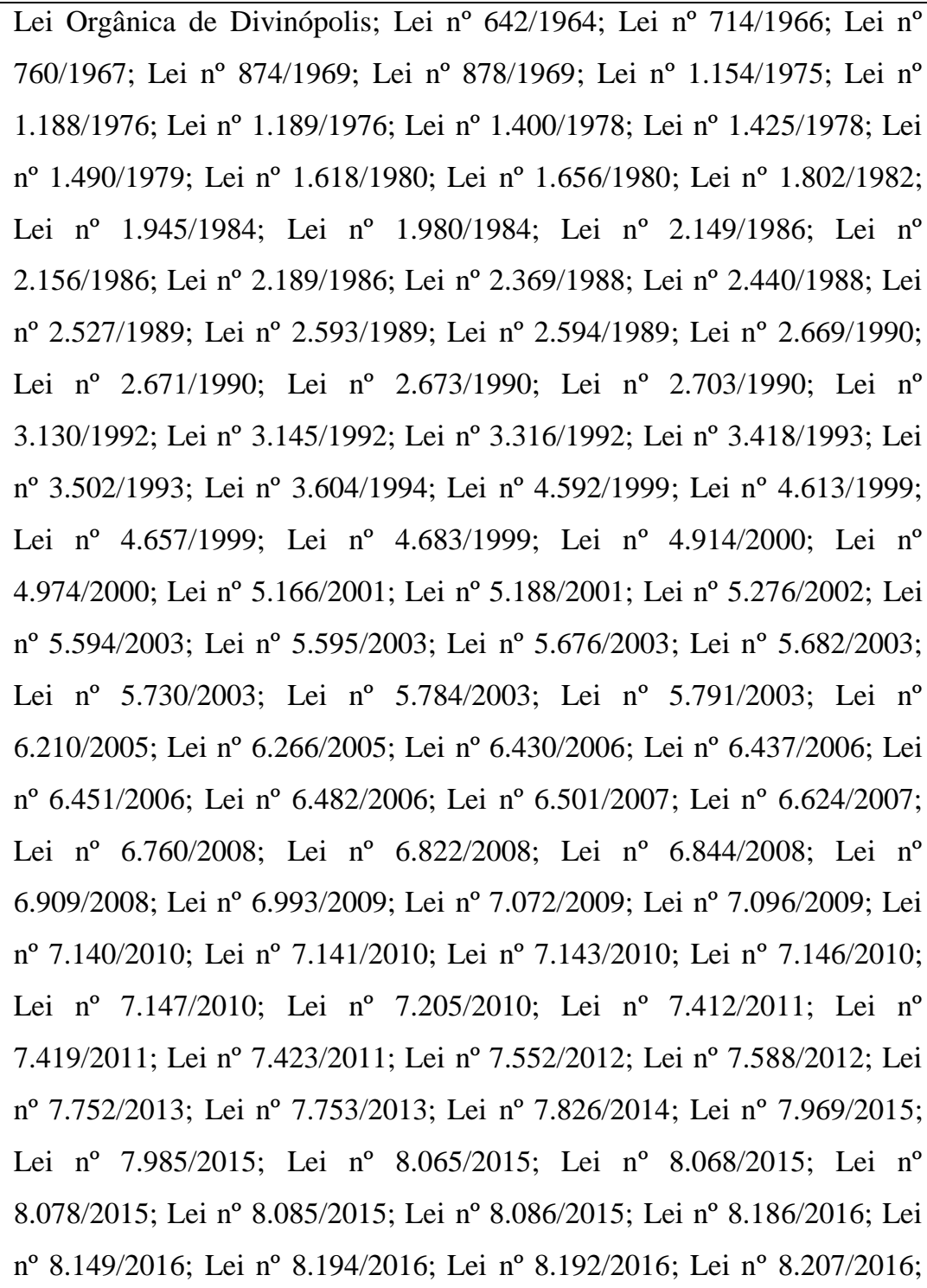 \\
\hline
\end{tabular}

licere, Belo Horizonte, v.24, n.4, dez/2021. 


\begin{tabular}{|c|c|}
\hline & 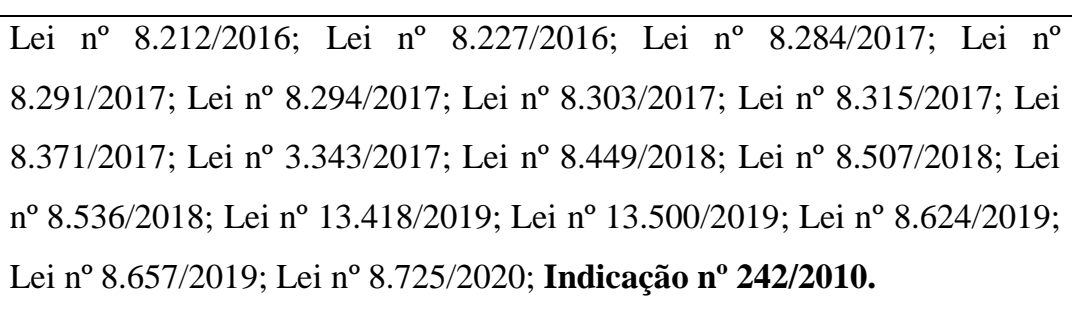 \\
\hline DECRETOS & $\begin{array}{l}\text { Decreto 1.200/1985; Decreto 10.740/2012; Decreto } \mathrm{n}^{\circ} 12.714 / 2017 \text {; } \\
\text { Decreto } \mathrm{n}^{\circ} 13.530 / 2019 ; \text { Decreto } \mathrm{n}^{\circ} 13.531 / 2019 ; \text { Decreto } \mathrm{n}^{\mathrm{o}} 13.532 / 2019 ; \\
\text { Decreto } \mathrm{n}^{\circ} \text { 13.550/2019. }\end{array}$ \\
\hline
\end{tabular}

Fonte: Dados da pesquisa

\section{Análise dos Documentos}

A análise documental foi realizada com a finalidade de revisar criteriosamente os documentos obtidos do município, a fim de identificar e classificar os espaços e equipamentos públicos de acordo com as suas finalidades (conteúdos) ou possuir mais de uma finalidade.

A partir da identificação e localização dos espaços e equipamentos, foi desenvolvida uma tabela no programa Excel com sete colunas intituladas como "Número de documentos", "Práticas de lazer", "Características", "Conteúdo", "Referência", "Localização" e "Regiões", todas elas categorias a serem analisadas nos documentos.

Após a construção da tabela, os espaços e equipamentos de lazer foram analisados e categorizados de acordo com os conteúdos do lazer propostos por Dumazedier (1979), Camargo (1998) e Schwartz (2003) (Quadro 2). Essa análise foi feita pela pesquisadora principal e logo após houve a revisão por uma segunda pesquisadora.

Quadro 2: Conteúdos de Lazer

\begin{tabular}{c|l}
\hline Físico-esportivo & \multicolumn{1}{|c}{ Atividades as quais prevalece o movimento } \\
\hline Manual & $\begin{array}{l}\text { Capacidade de manipulação, quer para transformar objetos ou } \\
\text { materiais, quer para lidar com a natureza. }\end{array}$ \\
\hline \multirow{2}{*}{ Intelectual } & $\begin{array}{l}\text { Contato com o real, as informações objetivas e explicações racionais. } \\
\text { A ênfase é dada ao conhecimento vivido e experimentado. }\end{array}$ \\
\hline \multirow{2}{*}{ Artístico } & $\begin{array}{l}\text { Relacionamento ao imaginário - as imagens, emoções, sentimentos. } \\
\text { Seu conteúdo é estético e configura a busca da beleza e do }\end{array}$ \\
\hline
\end{tabular}

licere, Belo Horizonte, v.24, n.4, dez/2021. 


\begin{tabular}{c|l}
\hline Social & encantamento. \\
\hline Turístico & $\begin{array}{l}\text { Fundamentado no relacionamento, os contatos face a face, o convívio } \\
\text { social. }\end{array}$ \\
\hline Virtual & $\begin{array}{l}\text { Quebra da rotina temporal e espacial, busca por novas paisagens, } \\
\text { pessoas e costumes. }\end{array}$ \\
\hline $\begin{array}{l}\text { Em função dos avanços tecnológicos e das novas práticas propiciadas } \\
\text { pela adesão ao ambiente virtual. }\end{array}$ \\
\hline
\end{tabular}

Fonte: Adaptado de Dumazedier (1979), Camargo (1998) e Schwartz (2003).

De acordo com localização dos espaços e equipamentos, foi identificada a distribuição nos bairros pertencentes as regiões Central, Sudeste, Nordeste, Noroeste, Sudoeste, Oeste, Nordeste Distante, Noroeste Distante, Sudoeste Distante, Sudeste Rural e Noroeste Rural do município de Divinópolis a partir do endereço disponível nos documentos analisados.

\section{Resultados e Discussão}

$\mathrm{Na}$ análise documental houve dificuldade em encontrar documentos referente aos espaços públicos de lazer, foi através de uma abordagem direta com o museu de documentos histórico de Divinópolis que obtivemos a indicação dos sites referentes as normativas citada neste estudo. As informações sobre os espaços públicos de lazer da cidade não são de fácil acesso a população, como no site ou redes sociais da prefeitura ou secretarias de cultura, esporte, dentre outras. Desta forma, obedecendo aos critérios de inclusão e exclusão, foram identificadas 109 Leis, 7 Decretos e 1 Indicação com informações dos espaços públicos de lazer deste município.

No estudo de Bettin; Peil e Melo (2018), os autores também relatam dificuldades de encontrar de informações e documentos para a identificação de espaços de lazer, considerando não haver registro pela Secretaria Municipal de Educação e Esportes do município de Pelotas sobre o mapeamento de espaços públicos, então os autores recorreram ao Plano Diretor para garantir a fidedignidade do estudo. 
A partir da identificação dos espaços públicos nas legislações, os mesmos foram classificados a partir da prática do conteúdo de lazer preponderante que o espaço proporciona (físico-esportivo, manual, intelectual, artístico, social, turístico, virtual). Os resultados desta classificação são representados na Tabela 1. Salienta-se que os espaços foram assim classificados, embora se entende que outros conteúdos de lazer possam ser desenvolvidos nos mesmos espaços, embora se tenha optado apenas pela classificação do conteúdo principal.

Quando observado o conteúdo físico-esportivo, foram identificados 21 espaços públicos destinados a essa classificação. Observando a prevalência de quadras poliesportivas e campo de futebol. Cerqueira et al. (2020) ressaltam que a prática de atividade física é um fator que proporciona a ocupação e a utilização dos espaços públicos. O mesmo autor ainda reforça que esses espaços são fundamentais para a socialização dos indivíduos e a vivência das práticas corporais.

Tabela 1: Espaços públicos de lazer categorizados quanto ao conteúdo de Lazer

\begin{tabular}{cc}
\hline Conteúdo do Lazer & Números de Espaços Públicos \\
\hline Social & 89 \\
Físico-Esportivo & 21 \\
Turístico & 14 \\
Artístico & 02 \\
Intelectual & 01 \\
Físico-Esportivo e Social & 01 \\
Manual & 00 \\
Virtual & 00 \\
\hline
\end{tabular}

Fonte: Dados da pesquisa

Com isso, Bonalume (2011) destaca que o esporte apresenta grande influência na vida das pessoas, sendo sua prática nos momentos de lazer imprescindíveis para a saúde, a educação, na formação de hábitos e valores, na intervenção com crianças e jovens para afastá-los das drogas. Embora as práticas esportivas e de lazer não possam 
ser encaradas como paliativo para os problemas sociais, pois se embasam em visões reducionistas e discriminatórias (CORREA, 2008), eles são importantes vias para o desenvolvimento dos indivíduos.

Ainda o ambiente esportivo pode proporcionar envolvimentos sociais tais como participação e desenvolvimento da comunidade, diversidade cultural, educação e saúde de jovens, práticas voluntárias, dentre outros (WALKER; PARENT, 2010). Tanto os veículos de comunicação quanto o mercado têm se encarregado de reforçar diariamente esses aspectos. Nesse sentindo o poder público ainda apresenta poucas iniciativas no desenvolvimento, em sua totalidade, de programas, projetos e ações, com o objetivo de garantir o acesso ao esporte na sua manifestação lazer para a comunidade em si.

É relevante citar que a disponibilização dos espaços públicos incentiva um conjunto de vivencias, que se compreendem nas práticas de atividades físicas, atividades culturais, descanso, divertimento, contemplação e dentre outras finalidades que contribui para o bem-estar e o desenvolvimento do indivíduo (CÁRDENAS; PUMARIEGA; TORRES, 2020).

Ao analisar o conteúdo social, de maior número de espaços identificados, foi possível perceber expressivo número de praças no município. Também foi identificado o local "Parque da Ilha", único classificado tanto no conteúdo social como no físicoesportivo, pois apresenta instalações para os estes dois fins, evidenciando a ausência de parques com possibilidade de diversidade de práticas na cidade. Os autores Ferreira, Carvalho e Paes de Lira (2019) acreditam que um dos grandes desafios atuais é possibilitar a ocupação do tempo livre com práticas que tenham benefícios quanto ao convívio saudável entre as pessoas, e a ocupação de diversos espaços da cidade para a realização de atividades prazerosas, recreativas e divertidas, proporcionando a 
socialização e reforçando a principal característica da cidade em relação à qualidade de vida dos seus habitantes.

Na perspectiva de Garbin (2019), os espaços públicos já não têm a mesma importância no convívio social das pessoas e em promover o reconhecimento coletivo de antigamente, quando a praça era o palco de manifestações da sociedade. Entretanto esses espaços ainda são representativos para a vida urbana, proporcionando um local destinado a prática do lazer, entre a opressão dos prédios e do movimento intenso do trânsito. Por isso, a qualidade de vida da cidade é mensurada pela dimensão da vida coletiva que é expressa nos espaços públicos. Sejam os aspectos sociais, econômicos, físicos ou culturais.

Já na concepção de Goettems e Bueno (2018),os espaços públicos de praças tem influência nos indivíduos, no qual expressam suas necessidades, desejos e anseios, possibilitando assim a troca de informações, definições de atitudes e posicionamento na vida urbana, assim a existência e valorização desses espaços tem grande relevância na comunidade atual. O que também faz parte da perspectiva de Menezes e Tângari (2019). relatando que as praças são um espaço livre público destinado ao ordenamento territorial, contendo uma função social que deve ser respeitada e valorizada pelo setor público em benefício da sua população.

No conteúdo turístico foram identificados 14 espaços públicos, no qual foram observados os patrimônios históricos do município de Divinópolis. Neste contexto é valido ressaltar a preservação da história local, contribuindo para a valorização da identidade cultural da cidade.

Ao realizar o mapeamento, a fim de determinar a essência dos locais e suas heranças culturais com a participação da comunidade pertencente, é possível visualizar a identidade deste lugar, como as práticas sociais, as tradições, as histórias e seus 
valores. Proporcionando também, consciencialização para as necessidades da sua preservação, transmissão e promoção (CABEÇA, 2018).

Quando classificado o conteúdo intelectual foi verificado apenas a "Biblioteca Pública Municipal Ataliba Lago". O conteúdo artístico também obteve apenas o "Espaço Cultural Usina Gravatá" e a pintura do "Cristo Crucificado". Para os conteúdos manuais e virtuais, não foram encontrados espaços públicos específicos para sua classificação, embora algumas ações relacionadas a estes conteúdos possam ser desenvolvidas em outros espaços. Além disso, espaços como bibliotecas públicas e espaços culturais são locais que normalmente possibilita uma diversidade de atividades, podendo contribuir no oferecimento de conteúdos intelectual, artístico, manual, virtual e turístico.

A partir da identificação, classificação do conteúdo de lazer e localização dos espaços e equipamentos, foi feita a distribuição territorial destes espaços nas regiões Central, Sudeste, Nordeste, Noroeste, Sudoeste, Oeste, Nordeste Distante, Noroeste Distante, Sudoeste Distante, Sudeste Rural e Noroeste Rural do município de Divinópolis. O número de espaços de lazer em cada região é apresentado na Tabela 2. A representação gráfica da distribuição dos espaços de lazer no território pode ser visualizada na Figura 3, possibilitando verificar se houve uma distribuição igualitária entre as regiões do município, ou carências no que diz respeito ao oferecimento de espaços e equipamentos destinados às práticas de lazer na cidade.

Tabela 2: Espaços públicos de lazer pertencentes a cada região de Divinópolis

\begin{tabular}{cc}
\hline Regiões & Números de Espaços Públicos \\
\hline Central & 27 \\
Sudeste & 22 \\
Noroeste rural & 19 \\
Nordeste & 16 \\
Noroeste & 15
\end{tabular}

licere, Belo Horizonte, v.24, n.4, dez/2021. 
Oeste

Figura 3: Mapeamento dos conteúdos de lazer do município de Divinópolis

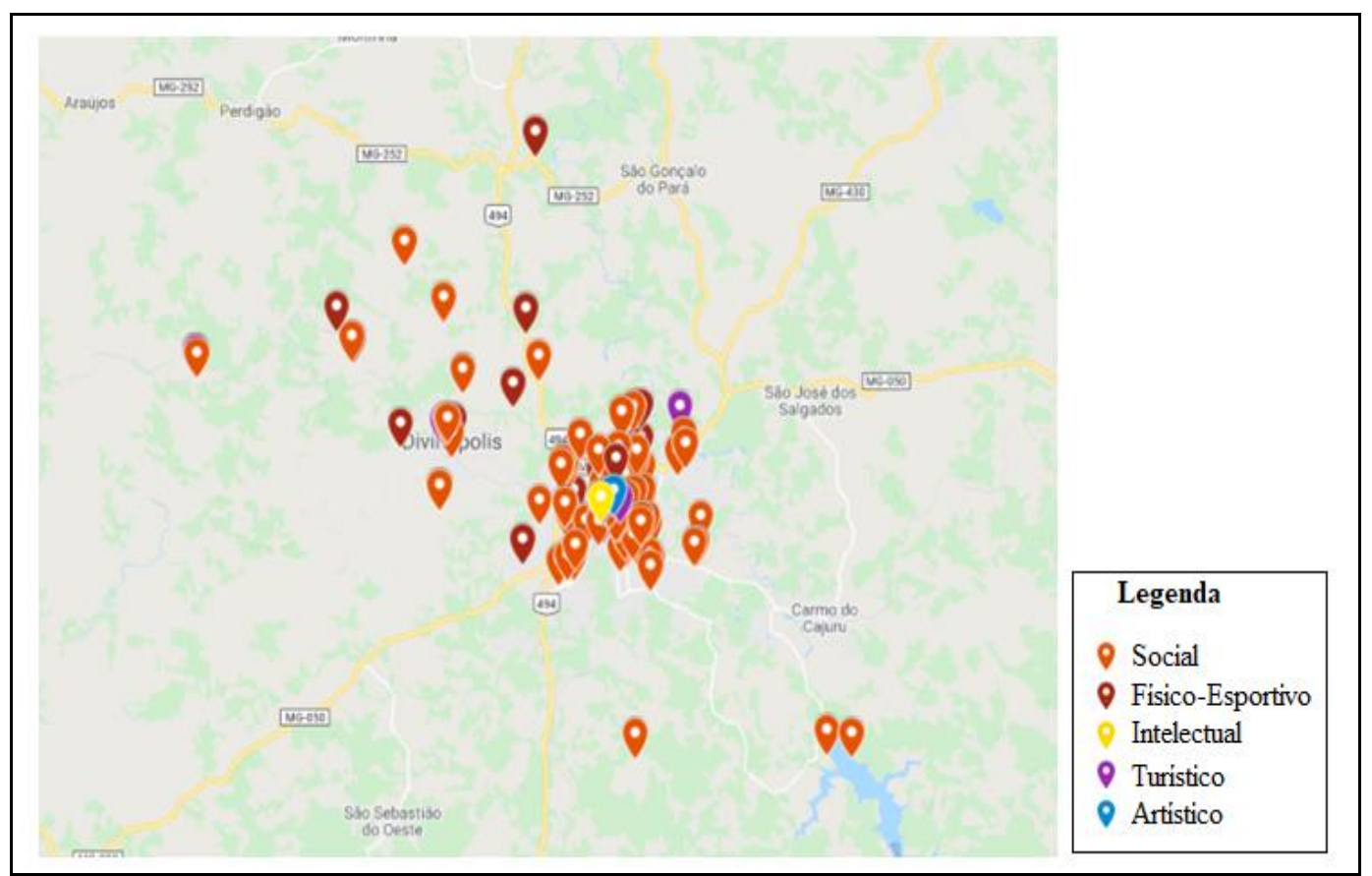

Fonte: Dados da pesquisa

Ao analisar as regiões, foi identificado que os espaços e equipamentos de lazer estão dispostos predominantemente na região Central e Sudeste, representados nas figuras 4 e 5, respectivamente. É possível verificar que a região Central apresenta diversidade de práticas, enquanto que na região Sudeste uma predominância de espaços de lazer de conteúdo social (Figura 4). 
Figura 4: Mapeamento dos conteúdos de lazer da Região Central do Município de Divinópolis

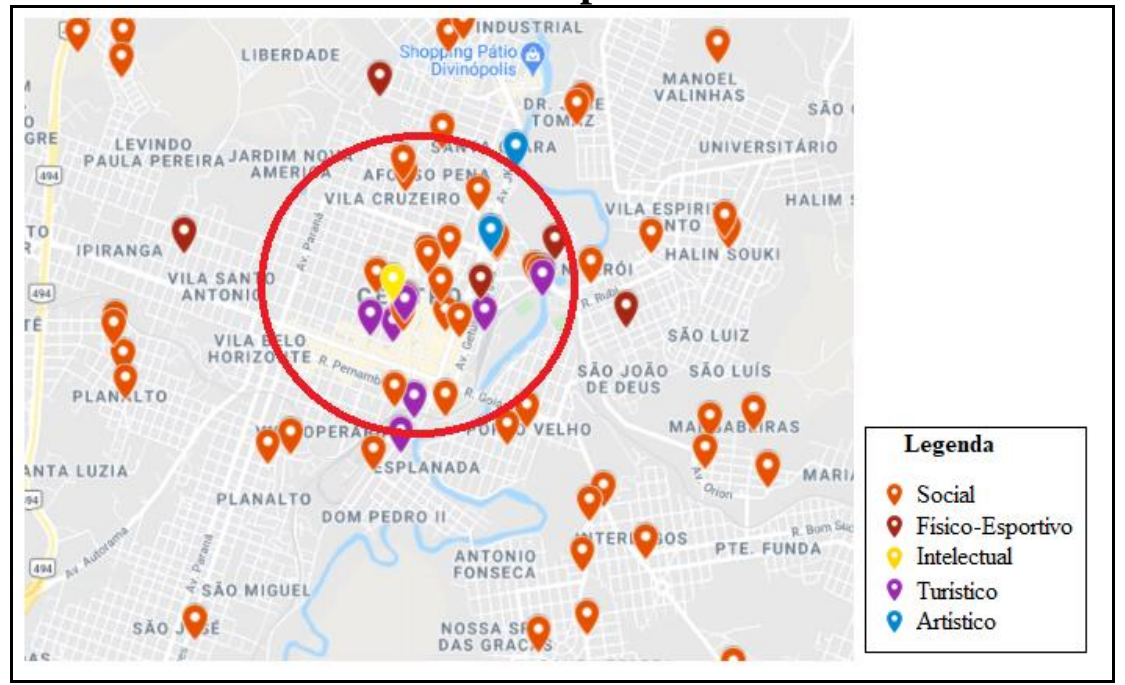

Fonte: Dados da pesquisa

Figura 5: Mapeamento dos conteúdos de lazer da Região Sudeste do município de Divinópolis

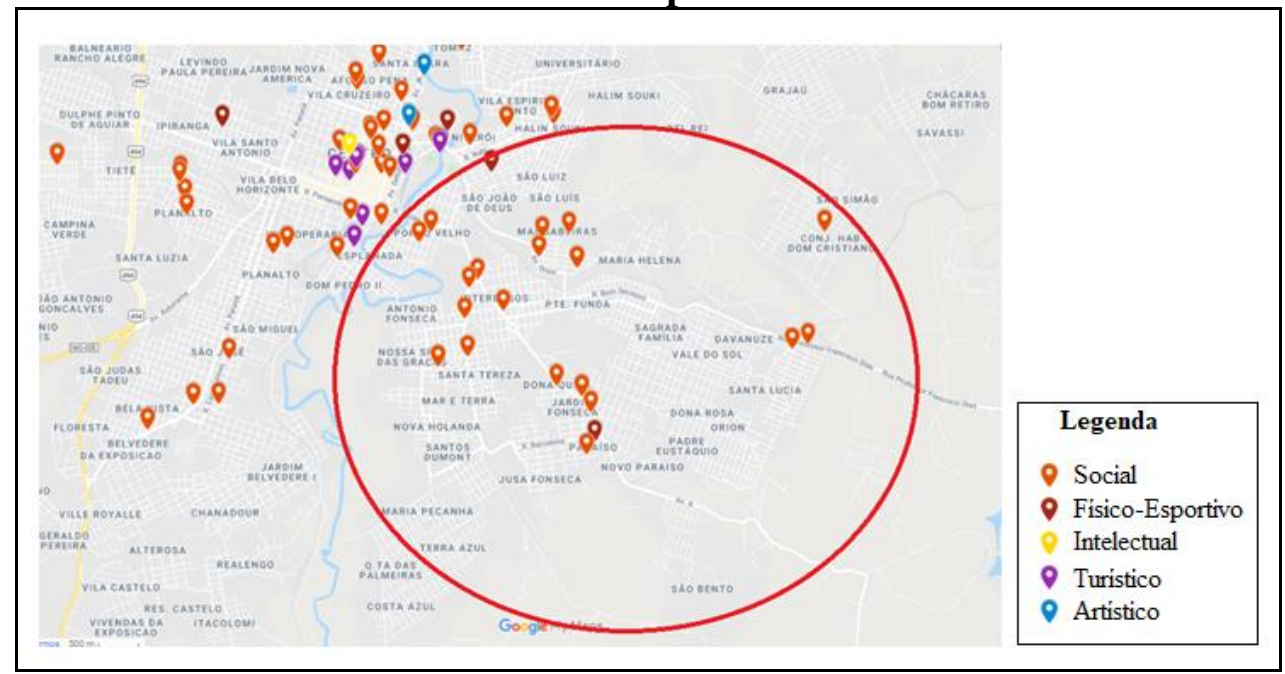

Fonte: Dados da pesquisa

França (2020) relata em seu estudo que as escolhas de espaços e tipos de lazer sofrem influência direta do contexto socioeconômico no qual o indivíduo está inserido. Essa forma de apropriação está relacionada as questões de nível de renda, distância entre o espaço público e a residência, meio de transporte, comercialização, dentre outros.

Pesquisas realizadas em outras realidades mostram panoramas semelhantes, ou seja, uma negligência por parte dos governos no que diz respeito à acessibilidade aos 
espaços de lazer e sua distribuição desigual no território, tanto nacional (MANTA, 2017; MARCELLINO et al., 2007; PEDROSO et al., 2011; PEDROSO; SILVA; SARMENTO, 2013) quanto internacionalmente (BILLAUDEAU et al., 2011; BURILLO et al., 2011; ESCOBAR; MONTOYA; GALINDO, 2018; HARRINGTON; JARVIS; MANSON, 2017; HILLSDON et al., 2007).

Nesse contexto, Silva et al. (2016) identificam que os indivíduos que moram próximo aos espaços de públicos de lazer tendem a frequentar mais e por isso devem haver políticas públicas que identifique as localidades e construa esses espaços a fim de possibilitar e dar oportunidade a toda a população de frequentar e ter diferentes vivências nesses ambientes. Ou seja, a distância e o número (disponibilidade) de espaços de lazer podem afetar o padrão de atividade da população (LIMA et al., 2013).

$\mathrm{Na}$ região Noroeste Rural foi possível perceber maior espaço territorial comparado as outras regiões, justificando assim as 19 áreas de lazer encontradas. As distribuições dessas áreas são pertencentes a 12 distritos diferentes que compõem o município de Divinópolis, contemplando principalmente o conteúdo social com as instalações como praças e o conteúdo físico-esportivo, com quadras poliesportivas.

O que difere da região Sudoeste rural, que apresenta apenas 04 espaços de lazer e tem uma área territorial considerável. Bezerra et al. (2020) corroboram em seu estudo identificando que a distribuição espacial dos equipamentos de esporte e lazer do município de Iguatu - Ceará apresentam uma homogeneidade de equipamento de lazer nas áreas centrais e a falta de equipamentos de lazer na zona rural.

Nas regiões Nordeste, Noroeste e Sudoeste foram identificados 16, 15 e 10 áreas de lazer, respectivamente. Foi observado que essas áreas apresentam com predominância os conteúdos sociais e físico-esportivo. Podemos perceber também que 
há uma boa distribuição das instalações desses espaços públicos, considerando que essas regiões tem localização próxima a região central de Divinópolis.

Já as regiões Oeste, Nordeste distante, Noroeste distante e Sudoeste distante é possível observar a escassez dos espaços públicos de lazer. Isso pode ter relevância com planejamento urbano que prioriza o desenvolvimento das regiões mais centralizadas. Mediante o exposto, Ferreira (2019), enfatiza a importância da discussão das áreas territoriais no planejamento das políticas públicas locais. Pois, diante dessa discussão os critérios de equidade devem ser relatados, com a possibilidade de identificar as desigualdades socioespaciais no interior do tecido urbano. Desta forma, será possível progredir na construção de um município mais inclusivo e sustentável.

Destaca-se também que apenas a partir da compreensão da distribuição dos recursos para tais ações e o entendimento das reais carências de cada região, poderá se estabelecer prioridades nas ações que deverão ser desempenhadas pelos governos (RAMOS et al., 1992).

Os autores Ribeiro; Mezzaroba e Santos (2018) acrescentam que o Estado deve se comprometer com o interesse público disponibilizando para a comunidade, principalmente de regiões periféricas, melhores condições de práticas de esporte e lazer, bem como políticas públicas que investissem na construção de praças, quadras poliesportivas, pista de ciclismo, dentre outros.

Na concepção de Eugenio (2019) o direito ao lazer vem sendo negado aos grupos vulneráveis da sociedade, mesmo com a presença de instalações, equipamentos e diferentes formas de lazer no espaço público, ainda não ocorre o incentivo e a educação para o lazer por parte do Estado, que também não apresenta políticas públicas como função de facilitar ou melhorar o acesso aos espaços e equipamentos disponíveis para a comunidade.

licere, Belo Horizonte, v.24, n.4, dez/2021. 


\section{Considerações Finais}

Podemos perceber a partir dos dados analisados, que a região Central do município de Divinópolis apresenta uma diversidade nos conteúdos de lazer e também a predominância (concentração) desses espaços públicos. A região Sudeste também apresentou uma alta concentração de conteúdos de lazer, entretanto com predominância nos conteúdos sociais. É relevante ressaltar que a cidade apresenta má distribuição dos espaços públicos de lazer, bem como a escassez de vários conteúdos do lazer em determinadas regiões. Desta forma, as regiões com localizações periféricas são exemplos da falta de políticas públicas que se preocupem com essa temática.

Esta pesquisa apresentou limitações, principalmente no que se referiu à coleta de dados, já que as informações a respeito dos espaços públicos de lazer não estão à disposição nos meios de comunicação oficiais do município, tornando o acesso da população à esta informação também dificultosa.

Como implicações práticas, esta pesquisa poderá contribuir com as políticas públicas municipais de Divinópolis, servindo de base para a compreensão do acesso da população as práticas de lazer, além de fomentar discussões acerca da falta de atenção a certos grupos periféricos. Para além da implicação teórica, de contribuir com o campo de estudos em lazer e do conhecimento do contexto das práticas de lazer na região centro-oeste de Minas Gerais.

Indicamos para pesquisas futuras a abordagens da qualidade desses espaços de lazer, com visitas in locus, com o objetivo de investigar se há conservação dos mesmos, e também a identificação e análise das ações, projetos e programas desenvolvidos pelo poder público nesses espaços e qual sua contribuição no oferecimento de possibilidades de práticas de lazer à população.

licere, Belo Horizonte, v.24, n.4, dez/2021. 


\section{REFERÊNCIAS}

BATISTA, M. H. A Restauração Católica no cotidiano da cidade: Círculo Operário, Imprensa e Obras Sociais em Divinópolis entre os anos 30 e 50.2002. $257 \mathrm{f}$. Dissertação (Mestrado) - Curso de Ciências Sociais, Pontifícia Universidade Católica de Minas Gerais, Belo Horizonte, 2002.

BETTIN, E. B.; PEIL, L. M. N.; MELO, M. P. Políticas públicas municipais de esporte, lazer e espaços públicos em Pelotas-RS na gestão 2009-2012. Pensar A Prática, [S.L.], v. 21, n. 1, p. 96-106, 29 mar. 2018.

BEZERRA, M. A. A. et al. Distribuição espacial e condições do uso de equipamentos de lazer da cidade de Iguatu-CE. Biomotriz, [S.L.], v. 14, n. 2, p. 13-22, 31 jul. 2020.

BILLAUDEAU, N. et al. Investigating disparities in spatial accessibility to and characteristics of sport facilities: Direction, strength, and spatial scale of associations with area income. Health and Place, v. 17, n. 1, p. 114 121, 2011.

BONALUME, C. R. O paradigma da intersetorialidade nas políticas públicas de esporte e lazer. Licere, Belo Horizonte, v. 14, n. 1, p. 1-26, mar. 2011. DOI: https://doi.org/10.35699/1981-3171.2011.782

BRASIL. Constituição da República Federativa do Brasil de 1988. Brasília, DF Presidência da República. Casa Civil. Diário Oficial da União. Subchefia para Assuntos Jurídicos, 1988.

- IBGE. Brasil em síntese, 2010. Disponível em: https://cidades.ibge.gov.br/brasil/mg/divinopolis/panoram. Acesso em: 20 mar. 2020.

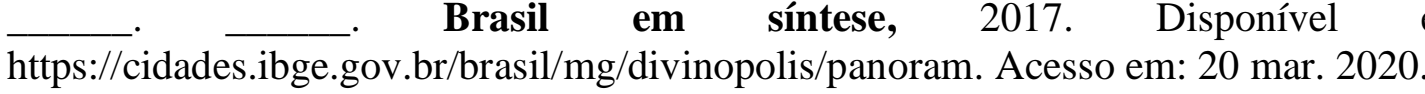

BURILLO, P. et al. The Influence of Economic Factors in Urban Sports Facility Planning: A Study on Spanish Regions. European Planning Studies, v. 19, n. 10, p. 1755-1773, 2011.

CABEÇA, S. M. Mapeamento Cultural: uma Metodologia Sustentada para o Património Cultural Imaterial. Revista Memoriamedia, Lisboa, v. 3, n. 5, p. 1-10, 2018.

CÂMARA MUNICIPAL DE DIVINÓPOLIS. Lei Orgânica do Município de Divinópolis - MG. Divinópolis. Câmara Municipal de Divinópolis-MG, 1998. Disponível em: www.divinopolis.mg.leg.br. Acesso em: 20 mar. 2020.

História de Divinópolis. 2018. Disponível em: https://www.divinopolis.mg.leg.br/sobre-divinopolis/historia. Acesso em: 27 mar. 2020.

CAMARGO, A. et al. Análise sobre os espaços de esporte e lazer no Morro da Formiga/RJ. Licere, v. 22, n. 2, p. 18-47, 2019. DOI: https://doi.org/10.35699/19813171.2019.13542.

CAMARGO, L. O. L. Educação para o lazer. São Paulo: Moderna, 1998.

licere, Belo Horizonte, v.24, n.4, dez/2021. 
CÁRDENAS, R. N., PUMARIEGA, Y. N., TORRES, C. D. P. Análise dos Espaços Públicos de Esporte e Lazer: um Ensaio a parti da Informação imagética. Licere, v. 23, n. 3, p. 666-686, 2020. DOI: http://doi.org/10.35699/2447-6218.2020.25514.

CERQUEIRA, P. G. de et al. Mapeamento de espaços públicos, práticas de lazer e atividade física de alunos e da comunidade no entorno do COLUNI/UFF. Revista Temas em Educação Física Escolar, Rio de Janeiro, v. 4, n. 2, p. 114-131, 2020.

CORREA, M. M. Projetos Sociais em Educação Física, Esporte e Lazer: Reflexões preliminares para uma gestão social. Revista Brasileira de Ciência do Esporte, v. 29, n. 3, p. 91-105, 2008.

DUMAZEDIER, J. Sociologia empírica do lazer. São Paulo: Perspectiva, 1979.

ESCOBAR, D. A.; MONTOYA, J. A.; GALINDO, J. A. Coverage Evaluation for Recreational and Cultural Facilities through Accessibility in Pitalito, Colombia. Contemporary Engineering Sciences, v. 11, n. 84, p. 4147-4158, 2018.

EUGÊNIO, J. O. Reflexões sobre o lazer e a mulher em situação de rua de Belo Horizonte - MG. In: GOMES, C. L. et al. (org.). COLÓQUIO INTERDISCIPLINAR DE ESTUDOS DO LAZER, 1, Belo Horizonte. Anais... EEFFTO/CELAR, 2019. p. 119-125.

FERREIRA, C. M.; CARVALHO, R. S.; LIRA, N. J. P. Práticas de esporte e lazer nas políticas públicas da cidade de Aracaju. Lecturas: Educación Física y Deportes, Uruguay, v. 24, n. 252, p. 1-21, maio 2019.

FERREIRA, R. N. Vulnerabilidade social e acesso a equipamentos públicos de educação infantil, cultura e lazer no município de Belo Horizonte - MG. Geoingá: Revista do Programa de Pós-Graduação em Geografia, Maringá, v. 11, n. 2, p. 4-27, 2019.

FRANÇA, J. P. Espaço público de lazer e turismo na cidade contemporânea: BelémPA. Paper do Naea, Pará, v. 29, n. 1, p. 156-171, 2020.

GARBIN, R. Praça da Bandeira: espaço público ou sistema viário? In: VIEIRA, M. S. (org.). Panorama dos Espaços Públicos de Erechim-RS. Palhoça: Editora Unisul, 2019. p. 181-189.

GIL, A. C. Como Elaborar Projetos de Pesquisa. 4. ed. São Paulo: Atlas, 2002.

GOETTEMS, R. F.; BUENO, A. P. Mapeamento e análise dos espaços de praça da cidade de Joinville - SC. Arq.Urb, São Paulo, v. 1, n. 22, p. 93-109, ago. 2018.

HARRINGTON, D. W.; JARVIS, J. W.; MANSON, H. Parents' Perceived Barriers to Accessing Sports and Recreation Facilities in Ontario, Canada: Exploring the Relationships between Income, Neighbourhood Deprivation, and Community. International Journal of Environmental Research and Public Health, v.14, n. 1272, p. 1-15, 2017.

HILLSDON, M. et al. Equitable Access to Exercise Facilities. American Journal of Preventive Medicine, v. 32, n. 6, p. 506v. 32, n. 6, p. 506-508, 2007.

licere, Belo Horizonte, v.24, n.4, dez/2021. 
LIMA, D. M. M. C. O espaço de todos, cada um no seu lugar: o uso dos espaços públicos destinados ao lazer em Natal. In: CARVALHO, J. E. (ed.). Lazer no espaço urbano: Transversalidade e novas tecnologias. Curitiba: Champagnat, 2006.

LIMA, A. V. et al. Distância percebida até as instalações de lazer e sua associação com a prática de atividade física e de exercícios em adolescentes de Curitiba, Paraná, Brasil. Cadernos de Saúde Pública, v. 29,n. 8, p. 1507-1521, ago. 2013.

MANTA, S. W. Espaços públicos e estrutura para atividade física no lazer em Florianópolis: Distribuição, qualidade e associação com a renda socioeconômica dos setores censitários. (Dissertação de Mestrado), Universidade Federal de Santa Catarina, 2017.

MARANHO, M. C. et al. Desenvolvimento de uma metodologia para as pesquisas de mapeamento de espaços de esporte e lazer de Ponta Grossa, Paraná: um relato de experiência. Revista Stricto Sensu, [S.L.], v. 4, n. 1, p. 52-66, 30 jun. 2019.

MARCELlinO, N. C. et al. Espaços e Equipamentos de Lazer em Região Metropolitana. Curitiba: Opus, 2007. 120 p.

Lazer, Espaço Urbano e Transversalidade. In: CARVALHO, J. E. (ed.). Lazer no Espaço Urbano: Transversalidade e Novas Tecnologias. Curitiba: Champagnat, 2006.

MENEZES, A. P.R.; TÂNGARI, V.. Ocupando praças - disputa de direitos entre a saúde e o lazer. SIMPOSIO BRASILEIRO DE QUALIDADE DO PROJETO NO AMBIENTE CONSTRUÍDO, [S.L.], p. 164-180, 30 out. 6. 2019. Anais... 2019.

PEDROSO, C. A. M. Q; SILVA, F. P. MENEZES, V G. SARMENTO, J P Planejamento de equipamentos esportivos na cidade: os parques urbanos do Recife PE/Brasil. Revista Intercontinental de Gestão Desportiva, v. 1, n. 1, p. 15 32, 2011.

; SILVA JR., E. L. L.; SARMENTO, J. P. Análise das instalações de lazer esportivo da região político administrativa 6 da cidade do Recife/PE Brasil. Revista Intercontinental de Gestão Desportiva, v. 3, n. 1, p. 64 78, 2013.

PREFEITURA MUNICIPAL DE DIVINÓPOLIS. Nossa Cidade. Disponível em: https://www.divinopolis.mg.gov.br/portal/cidade/13/historia/. Acesso em: 27 mar. 2020.

Projeto de Lei Complementar em 004/2013. Estabelece o Plano Diretor do município de Divinópolis e dá outras providências.Divinópolis/MG Prefeitura Municipal de Divinópolis, , 2013. Disponível em: https://planodiretordedivinopolis.wordpress.com/2013/03/21/mapa-das-regioes-dedivinopolis/.

RAMOS, J. et al. Actitudes ante la política de planificación de instalaciones deportivas: una escala de medida. Revista de Psicologia del Deporte, v. 1, p. 37-51, 1992.

RIBEIRO, S. D. D.; MEZZAROBA, C.; SANTOS, M. B. Espaços públicos de esporte e lazer no contexto das cidades: um olhar midiático. REUNIÃO ANUAL DA SBPC, 70. Anais... Maceió, v. 1, n. 1, p. 1-3, jul. 2018. 
RODRIGUES, E. H. C.; BRAMANTE, A. C. O Espaço Na Construção De Uma Política De Lazer - Estudando Sorocaba / Sp. Revista Brasileira de Ciências do Esporte, v. 24, n. 3, p. 23-37, 2003.

SANTOS, A. T. S.; BARBOSA, T. I.; MUNIZ, T. S. Mapeamento dos Espaços Públicos Urbanos de Lazer na Cidade de Capitão Poço - PA. Revista Brasileira de Estudos do Lazer, Belo Horizonte, v. 3, n. 5, p. 3-18, dez. 2018.

SCHWARTZ, G. M. O conteúdo virtual do lazer: contemporizando Dumazedier. Licere, Belo Horizonte, v. 2, n. 6, p. 23-31, 2003.

SILVA, E. A. P. C. et al. Percepção da qualidade do ambiente e vivências em espaços públicos de lazer. Revista Brasileira de Ciências do Esporte, [S.L.], v. 38, n. 3, p. 251-258, jul. 2016.

TEIXEIRA, T. C. M. Lazer e Recreação nos Espaços Públicos. In: SILVA, T. A. DA C.; PINES JÚNIOR, A. R. (eds.). Lazer e Recreação Conceitos e Práticas Culturais. Rio de Janeiro: Wak, 2018.

WALKER, M.; PARENT, M. M. Toward an integrated framework of corporate social responsibility, responsiveness, and citizenship in sport. Sport Management Review, v.13, p. 198-2013, 2010.

\section{Endereço das Autoras:}

Isabella Carolina Silva Pereira

Endereço Eletrônico: isabellacarolinaef@ hotmail.com

Cacilda Mendes dos Santos Amaral

Endereço Eletrônico: cacilda.amaral@uemg.br 